\title{
False negative results from using common PCR reagents
}

\author{
Dean J Bacich, Kathryn M Sobek, Jessica L Cummings, Allison A Atwood and Denise S O'Keefe
}

\begin{abstract}
Background: The sensitivity of the PCR reaction makes it ideal for use when identifying potentially novel viral infections in human disease. Unfortunately, this same sensitivity also leaves this popular technique open to potential contamination with previously amplified PCR products, or "carry-over" contamination. PCR product carryover contamination can be prevented with uracil-DNA-glycosylase (UNG), and it is for this reason that it is commonly included in many commercial PCR master-mixes. While testing the sensitivity of PCR assays to detect murine DNA contamination in human tissue samples, we inadvertently discovered that the use of this common $P C R$ reagent may lead to the production of false-negative PCR results.

Findings: We show here that contamination with minute quantities of UNG-digested PCR product or any negative control PCR reactions containing primer-dimers regardless of UNG presence can completely block amplification from as much as $60 \mathrm{ng}$ of legitimate target DNA.

Conclusions: These findings could potentially explain discrepant results from laboratories attempting to amplify MLV-related viruses including XMRV from human samples, as none of the published reports used internal-tube controls for amplification. The potential for false negative results needs to be considered and carefully controlled in PCR experiments, especially when the target copy number may be low - just as the potential for false positive results already is.
\end{abstract}

\section{Findings}

Carry-over contamination can be prevented by incorporating uracil instead of thymine into the PCR product, then treating with uracil-DNA-glycosylase (UNG) prior to initiating subsequent PCR reactions [1]. The UNG degrades DNA containing uracil, thereby degrading contaminating PCR products while leaving non-uracil DNA (ie. target DNA) intact. This method is so effective that several major brands of Taq and Taq master-mixes include this enzyme and replace dTTP with dUTP. In addition the enzyme is sold separately and as part of kits designed to prevent carry-over contamination.

Xenotropic Murine leukemia virus Related Virus (XMRV) was isolated from patients with prostate cancer in 2006, and since that time many reports have either identified XMRV or the highly related murine leukemia viruses (MLVs) in various patient cohorts. However, many reports have been unable to find either of these types of

\footnotetext{
* Correspondence: okeefeds@upmc.edu

* Correspondence: okeefeds@upmc.edu
Department of Urology, University of Pittsburgh, 5200 Centre Avenue, Pittsburgh, PA 15232, USA
}

(c) 2011 O'Keefe et al; licensee BioMed Central Ltd. This is an open access article distributed under the terms of the Creative Commons Attribution License (http://creativecommons.org/licenses/by/2.0), which permits unrestricted use, distribution, and reproduction in any medium, provided the original work is properly cited. viruses. Mice, particularly strains of mice used in laboratory research, carry 20-40 copies of MLV-type viruses. Therefore MLV-type viral DNA detected in patient samples could be due to actual MLV infection of patient tissue or contamination of patient samples with mouse DNA. We developed an assay to detect femtogram level contamination of murine DNA in human DNA samples. This sensitivity is necessary because MLV-related viruses found in human populations seem to be present at very low levels. Therefore low levels of murine DNA contamination could give rise to false-positive results.

Use of Uracil-DNA-glycosylase inhibits amplification of legitimate target DNA in the presence of low levels of PCR carry-over contamination

We developed an assay to detect contaminating mouse DNA in human tissue samples using the Gene Expression master-mix from Applied Biosystems (Life Technologies Corp.). This master-mix is routinely employed by labs that carry out Taqman gene expression assays, and it contains uracil-DNA-glycosylase and dUTP to prevent 
PCR carry-over contamination. Elimination of any potential PCR product contamination is achieved by a twominute incubation at $50^{\circ} \mathrm{C}$ prior to inactivation of the enzyme during the initial denaturation of the PCR reaction. When testing to confirm that PCR carry-over would be eliminated, we inadvertently discovered that contamination with as little as 10 picoliters of PCR product was able to inhibit amplification of legitimate, albeit low copy number target (Figure 1a). To determine both the specificity as well as the effectiveness of the inhibition of amplification of legitimate target, we intentionally contaminated mouse DNA with PCR product generated using the Gene Expression master-mix. As shown in Figure $1 \mathrm{~b}$, when we attempted to amplify two unrelated targets from 80 nanograms of mouse DNA, deliberate contamination with a third unrelated PCR product (mouse mitochondrial DNA), resulted in significant inhibition of amplification, even when the amount of PCR product added was just one nanoliter. Furthermore, when PCR product that was the same as the target reaction was deliberately spiked into the DNA samples and the PCR was performed with a master-mix containing UNG, it almost completely inhibited amplification from $60 \mathrm{ng}$ of legitimate target, even at a final dilution of 1:25, 000 and 1:25 million (Figure $1 \mathrm{c}$ and $1 \mathrm{~d}$, respectively). Therefore accidental cross-contamination with previously generated PCR product can significantly inhibit legitimate target amplification, even when the true target is present at a very high copy number, and the contamination is minute.

\section{Primer-dimers from previously generated reactions can also inhibit legitimate target amplification, regardless of the presence of uracil-DNA-glycosylase}

Presumably inhibition of the PCR reaction is due to the competition for genomic DNA target binding between the primers and degraded PCR products. Based upon this reasoning we tested if primer-dimers generated from a negative control PCR reaction could inhibit subsequent PCR amplification. We performed this experiment using a master-mix with and without UNG, hypothesizing that the presence of primer-dimers may be sufficient to inhibit PCR amplification. For this experiment we intentionally contaminated mouse DNA with PCR primer-dimers generated from a PCR reaction using either a UNG- or nonUNG-containing master-mix. The negative PCR reaction was able to inhibit the subsequent PCR reaction at a $10^{-5}$ dilution if the same primers were used in the subsequent reaction, but they did not inhibit amplification of an unrelated target (Figure 2a). There was no difference between UNG and non UNG master-mixes (Figure $2 \mathrm{a}$ and $2 \mathrm{~b}$ ). Given that the primer-dimers of the negative PCR reaction

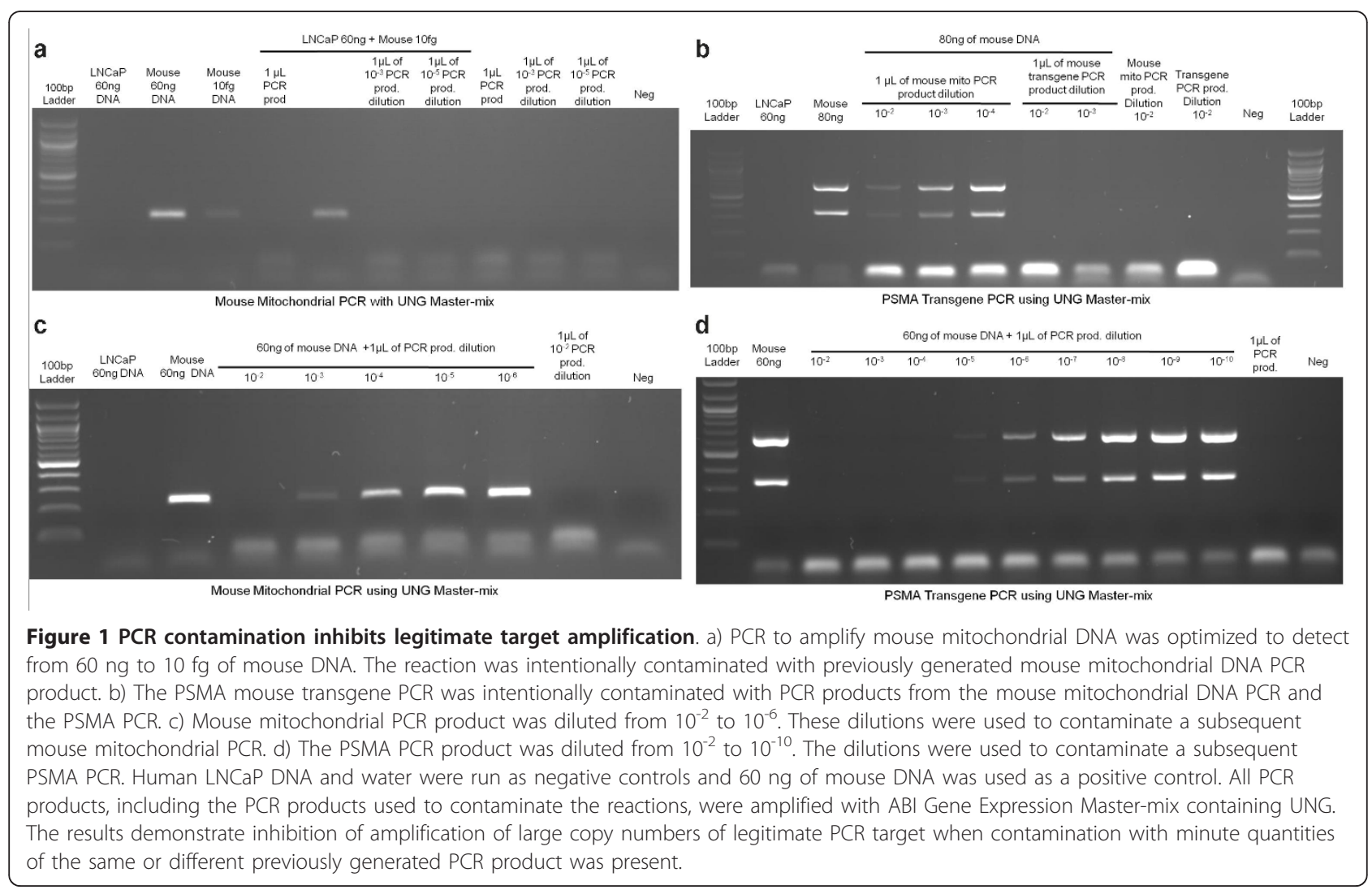




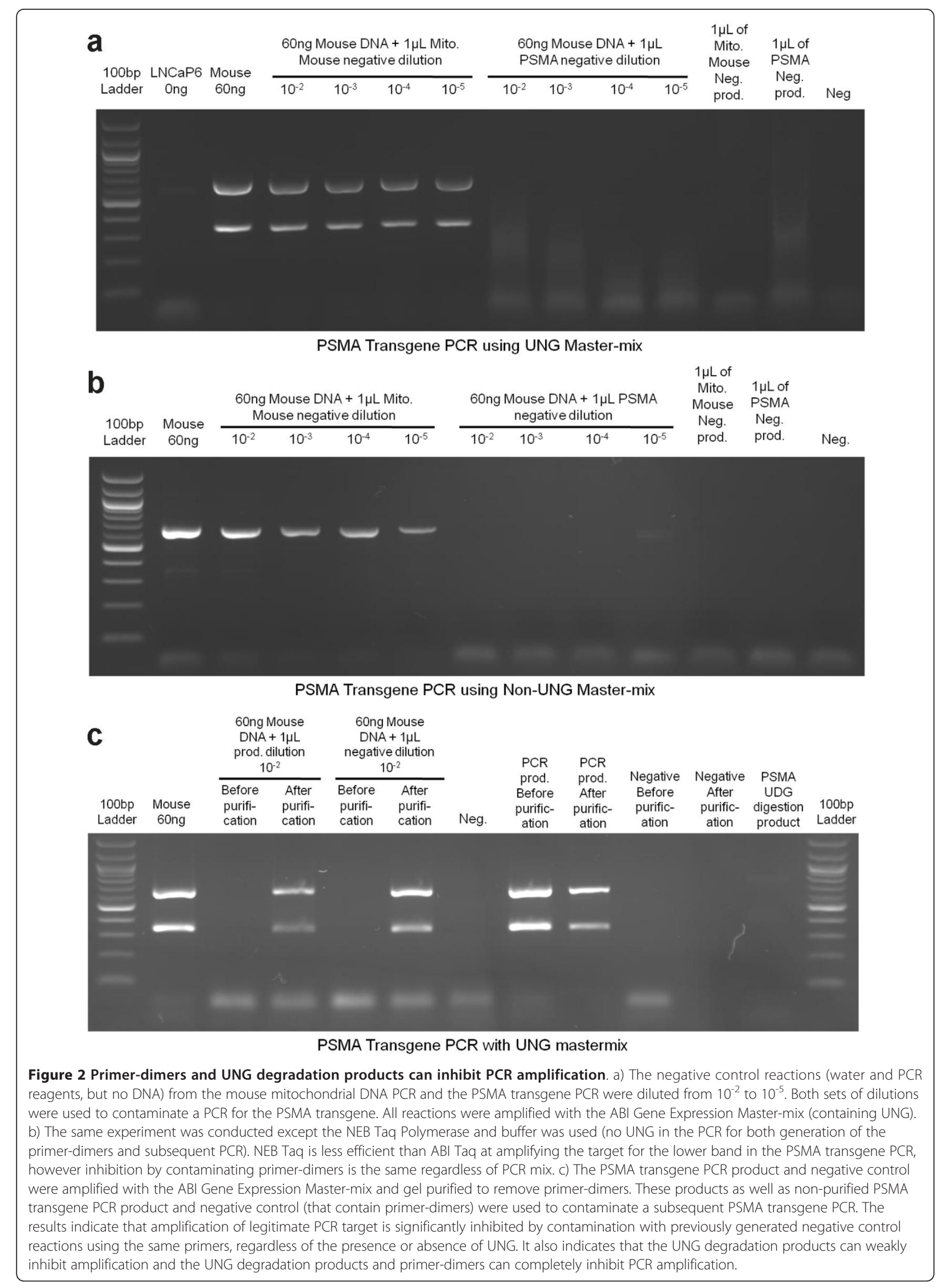


were able to effectively inhibit subsequent PCR reactions, we then tested if it was just the primer-dimers in the UNG containing PCR that provide the inhibition or if the degraded PCR amplicon was also capable of inhibiting the subsequent PCR reaction. By gel isolating the UNG incorporated PCR product to remove the primer-dimers, and then spiking $\left(10^{-2}\right.$ dilution) this into a fresh PCR we were able to demonstrate that this weakly inhibited the subsequent PCR (Figure 2c).

\section{Primer dimers from previously generated reactions demonstrate a strong inhibitory effect on legitimate target amplification of an MLV-carrying plasmid}

Next we wanted to examine the extent of primer-dimer inhibition of PCR product formation when specifically amplifying MLVs. We performed a PCR on plasmid DNA containing the Gag region of an MLV using primers within this Gag region. We started with $2 \times 10^{6}$ copies $(6$ $\mathrm{pg}$ ) of plasmid DNA and contaminated this PCR with different dilutions of either unrelated target primer-dimers (PSMA transgene) or Gag PCR primer-dimers from previous PCR reactions. As seen in Figure 3a, the unrelated target primer-dimers do not inhibit PCR product formation whereas contamination with Gag PCR primer-dimers completely inhibits PCR product formation up to $10^{-5}$ dilution and demonstrates weak inhibition of PCR product formation through $10^{-9}$ dilution.

MLVs previously found to be present in patient samples have been observed at very low levels. Therefore we wanted to examine the inhibitory effect that minute levels of primer-dimer contamination $\left(10^{-7}\right.$ dilution) can have on Gag PCR product formation from MLVs that are present at low copy number. Figure $3 \mathrm{~b}$ demonstrates that contamination of MLV present at 200, 000 copies or less with $10^{-7}$ dilution of Gag PCR primer-dimers from a previous PCR reaction almost completely inhibits PCR product formation. This data suggests that contamination with extremely small quantities of primer-dimers generated from previous PCR reactions can inhibit PCR product formation, thus leading to false negative results.

Taken together, these data suggest that inhibition of legitimate target occurs from UNG-digested PCR products or from contamination with primer-dimers from a previous PCR reaction, regardless of the presence of UNG. Thus contamination from any previous PCR samples can result in either false positives (which may or may not be detected in the negative control depending upon the samples that are contaminated and whether UNG is used) or false negatives which will not be detected using standard PCR controls.

\section{Discussion and Conclusions}

As these results could potentially explain some of the discrepancies in amplification of MLV-related viruses from different laboratories, we surveyed these publications to attempt to determine if the authors used UNG-containing master-mixes. Of concern, despite the importance of the actual PCR methods used to amplify these potentially novel viruses, we were unable to determine the type of Taq or master-mix used in 11 of 38 publications. Of the remaining 27 publications, 13 studies used Taq or mastermixes likely containing UNG (it was present in 8 studies [2-9] and possibly used in the remaining 5 studies [10-14] that we examined). Therefore contamination at either the individual sample level or in the PCR reaction itself could have inhibited amplification of legitimate target, especially if the target is found at low levels. Additionally, as shown in Figure 2, regardless of the presence of UNG, PCR can be inhibited if there is even a minute amount of contamination from previous (negative) PCR reactions.

Based on our data, we could speculate that low levels of PCR product contamination may not be sufficient to significantly block amplification of the positive control in these reactions, especially if the positive control is the target cloned into a plasmid and present at a high copy number. In the majority of the studies commented on in this manuscript, the positive control used was an XMRV plasmid, and most papers were not clear about the amount of plasmid used for control amplification. Therefore, amplification of the high copy number positive control could occur while samples positive for a low copy number virus could be inhibited by carry-over PCR contamination.

To circumvent the potential for PCR inhibition, a positive control included in each PCR reaction is necessary to confirm that the PCR is not inhibited. To accomplish this, a synthetic target template with identical primer-binding sites but different size could be constructed, and spiked into each test sample. This would result in potential amplification of two bands: one band to detect the target DNA and the other to detect the synthetic target. In addition, the copy number of the synthetic target spiked into the test samples would need to be at the level of detection of the assay, so as any inhibition would result in lack of amplification. None of the $38 \mathrm{MLV}$-related publications we examined used internal PCR controls. Given the data presented in this manuscript, we would propose that in cases such as the debate regarding the existence of novel infectious viruses, failure to find a virus is not the equivalent of evidence against its existence. The potential for false negative results needs to be considered and carefully controlled in PCR experiments, just as the potential for false positive results already is.

\section{Methods \\ DNA extraction}

Human LNCaP cell line DNA was extracted with the DNeasy ${ }^{\circledR}$ Blood \& Tissue Kit (Qiagen). DNA from mouse tails was extracted with the Wizard SV Genomic DNA 


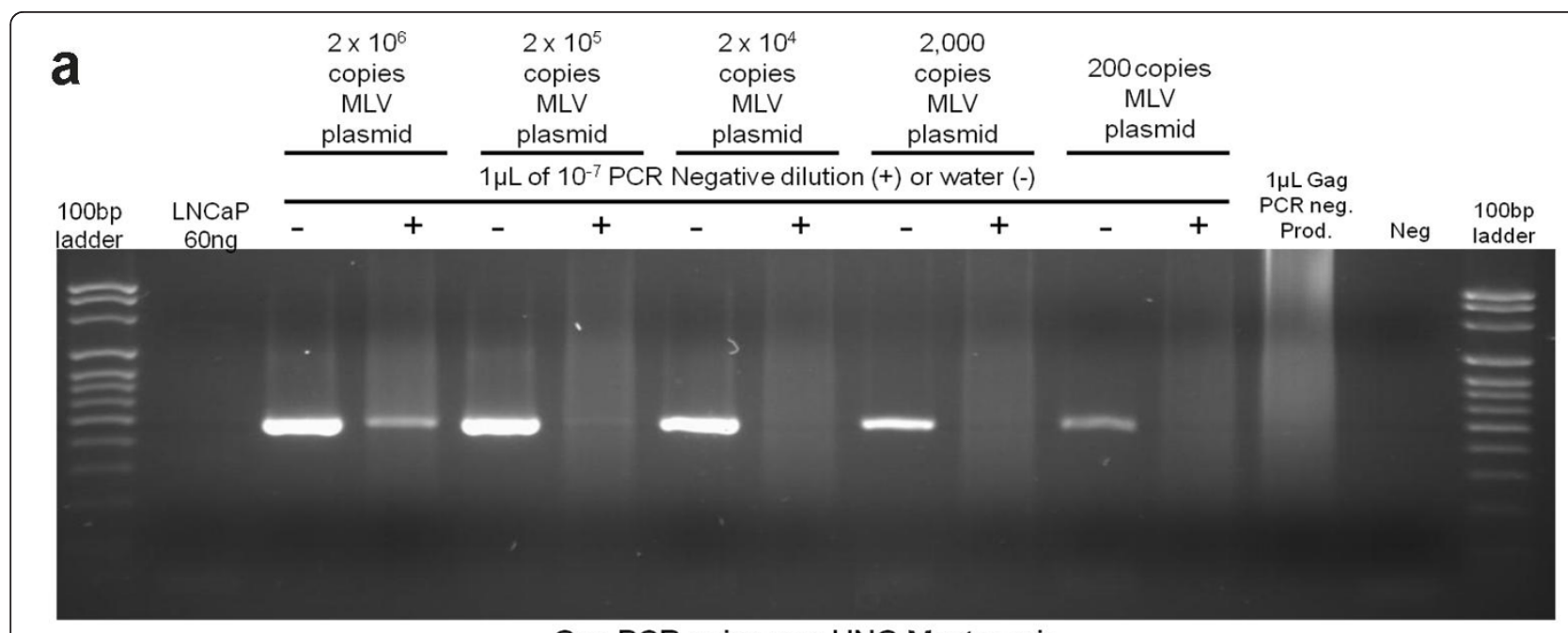

Gag PCR using non-UNG Master-mix

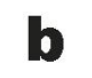

$2 \times 10^{6}$ copies MLV plasmid

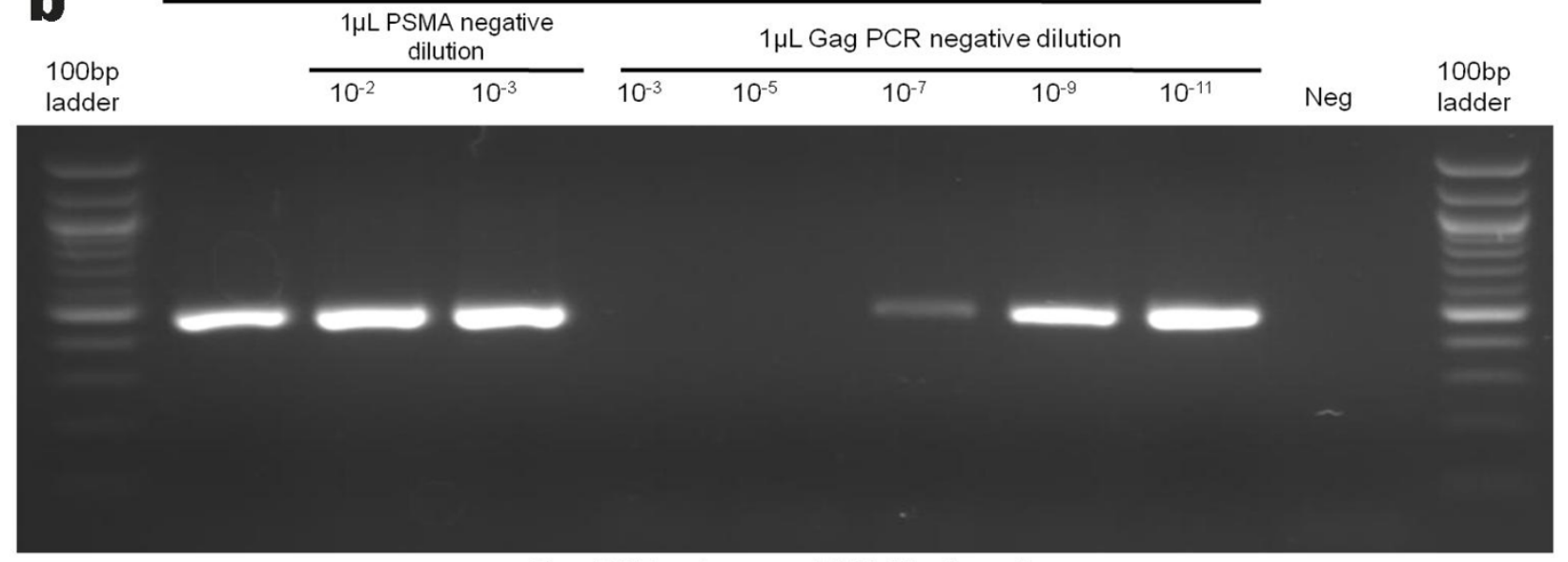

Gag PCR using non-UNG Master-mix

Figure 3 Primer-dimers from previously generated reactions demonstrate a strong inhibitory effect on legitimate target amplification of MLV Gag region. a) The negative control reactions (water and PCR reagents but no DNA) from the PSMA PCR and MLV Gag PCR were diluted as shown. Both sets of dilutions were used to contaminate a PCR for MLV Gag. The MLV Gag PCR used Titanium Taq Polymerase and buffer and the PSMA PCR used NEB Taq Polymerase and buffer, with both PCRs being non-UNG containing. b) A negative control reaction (water and PCR reagents but no DNA) from the MLV Gag PCR was diluted $1 \times 10^{-7}$. This PCR, which used non-UNG containing Titanium Taq Polymerase and buffer, was used to contaminate a subsequent MLV Gag PCR. The MLV-plasmid was used in decreasing copy number, as indicated.

purification system (Promega). Approval for mouse work was given by the University of Pittsburgh IACUC, under protocol \#1991385A, and the work was performed according to internationally accepted guidelines. In order to remove primer-dimers from the PSMA PCR product and negative control, the bands of the PCR product and negative control were cut from a $0.8 \%$ agarose gel. The GENECLEAN $^{\circledR}$ II Kit (Qbiogene) was used to purify the samples per manufacturer's instructions. Five microliters of the isolation products were electrophoresed on a $1.5 \%$ agarose gel to confirm the purified PCR and lack of primer-dimers.

\section{Mouse mitochondrial DNA, PSMA transgene, and MLV-Gag PCR}

All primer sequences are listed in Table 1.

Mitochondrial PCR: 60 ng of mouse DNA was amplified in a $25 \mu \mathrm{L}$ reaction containing $12.5 \mu \mathrm{L} 2 \times$ Gene Expression Master-Mix (Applied Biosystems), $0.5 \mu \mathrm{M}$ Mouse mito $\mathrm{F}$ primer, $0.5 \mu \mathrm{M}$ Mouse mito R primer, and $9.5 \mu \mathrm{L}$ of water. Two microliters of $30 \mathrm{ng} / \mu \mathrm{L}$ mouse DNA was added the reaction. The following cycle conditions were used: $50^{\circ} \mathrm{C}$ for 2 minutes (UNG incubation), $94^{\circ} \mathrm{C}$ for 10 minutes (AmpliTaq Gold Enzyme Activation), and 40 cycles of $95^{\circ} \mathrm{C}$ for 15 seconds and $60^{\circ} \mathrm{C}$ for 1 minute. The reactions were 
Table 1 Primer sequences used in these experiments

\begin{tabular}{cc}
\hline Primer Name & Primer sequence \\
\hline Mouse mito $F$ & 5'-ACTATCCCCTTCCCCATTTG-3' \\
\hline Mouse mito R & 5'-TGTTGGTCATGGGCTGATTA-3' \\
\hline S49 & 5'-CAGATATGTCATTCTGGGAGG-3' \\
\hline Inta & 5'-GTAGAAGAGAACTGCTGAGGA-3' \\
\hline S1368 & 5'-ATTCAATCCTGCTCAGACCC-3' \\
\hline AS2015 & 5'-AACACCATCCCTCCTCGAACC-3' \\
\hline MLV Gag F & 5'-CCTTGGGAGGGTCTCCTCAG-3' \\
\hline MLV Gag R & 5'-CAGA CGCGCCGCGCGGTTTC-3'
\end{tabular}

carried out in an Eppendorf Mastercycler personal thermocycler. The expected size of the PCR product is $\sim 230 \mathrm{bp}$. $\mathrm{PCR}$ reactions were run on a 1.5\% agarose/TBE gel.

Gag PCR: Varying amounts of plasmid DNA was amplified in a $25 \mu \mathrm{L}$ reaction containing $2.5 \mu \mathrm{L} 10 \times$ Titanium Taq PCR Buffer (Clonetech), 0.2 uL Titanium Taq (Clonetech), $0.2 \mathrm{mM}$ dNTPs, $0.5 \mu \mathrm{M}$ MLV Gag F primer, $0.5 \mu \mathrm{M}$ MLV Gag R primer, and $19.8 \mu \mathrm{L}$ of water. The following cycle conditions were used: $94^{\circ} \mathrm{C}$ for 1 minutes, 40 cycles of $\left[95^{\circ} \mathrm{C}\right.$ for 30 seconds and $68^{\circ} \mathrm{C}$ for 30 seconds], $68^{\circ} \mathrm{C}$ for 3 minutes. The reactions were carried out in an Eppendorf Mastercycler personal thermocycler. The expected size of the PCR product is $\sim 500 \mathrm{bp}$. PCR reactions were run on a $1.4 \%$ agarose/TBE gel.

PSMA transgene PCR: The PSMA PCR contains 2 sets of primers to amplify two unrelated targets from PSMA transgenic mice (the transgene and genomic control sequence). Sixty to eighty nanograms of transgenic mouse DNA was amplified in a $25 \mu \mathrm{L}$ reaction containing $12.5 \mu \mathrm{L} 2 \times$ Gene Expression Master-Mix (Applied Biosystems), $1 \mu \mathrm{M}$ S49, $1 \mu \mathrm{M}$ INTA, $1 \mu \mathrm{M}$ S1368, $1 \mu \mathrm{M}$ AS2015, $6.5 \mu \mathrm{L}$ of water, and $2 \mu \mathrm{L} 30 \mathrm{ng} / \mu \mathrm{l}$ to $40 \mathrm{ng} / \mu \mathrm{L}$ mouse DNA. The following cycle conditions were used: $50^{\circ} \mathrm{C}$ for 2 minutes (UNG incubation), $94^{\circ} \mathrm{C}$ for $10 \mathrm{~min}$ utes (AmpliTaq Gold Enzyme Activation), 35 cycles of $94^{\circ} \mathrm{C}$ for 30 seconds, $58^{\circ} \mathrm{C}$ for 30 seconds, and $72^{\circ} \mathrm{C}$ for 45 seconds. The expected product sizes are $\sim 600 \mathrm{bp}$ and $\sim 250$ bp and were electrophoresed on a 1.5\% agarose/ TBE gel.

The PSMA PCR was also amplified with non-UNG containing taq. Sixty nanograms of transgenic mouse DNA was amplified in $25 \mu \mathrm{L}$ reaction containing $0.5 \mathrm{U}$ Taq DNA Polymerase, 10× ThermoPol Reaction Buffer (New England BioLabs, Inc.), 0.4 mM dNTP (dATP, dTTP, dCTP, and dGTP), $1 \mu \mathrm{M}$ S49, $1 \mu \mathrm{M}$ INTA, $1 \mu \mathrm{M}$ S1368, and $1 \mu \mathrm{M}$ AS2015. The following cycle conditions were used: $94^{\circ} \mathrm{C}$ for 5 minutes, 35 cycles of $94^{\circ} \mathrm{C}$ for 30 seconds, $58^{\circ} \mathrm{C}$ for 30 seconds, and $72^{\circ} \mathrm{C}$ for 45 seconds.

Negative PCR products (only water added to the PCR reaction) of the mouse mitochondrial PCR, PSMA PCR, and Gag PCR were also diluted $10^{-2}$ through $10^{-11}$ and used to simulate contamination of subsequent PCR reactions. PCR products ranged from $4 \mathrm{ng} / \mu \mathrm{l}$ (PSMA PCR lower band) to $10 \mathrm{ng} / \mu \mathrm{l}$ for all other reactions, prior to dilution for use in simulated contamination experiments.

\section{Acknowledgements and Funding}

This study was funded by NIHR01CA138444 (DOK and DJB). KMS is supported by DOD Award PC101949. The U.S. Army Medical Research Acquisition Activity, 820 Chandler Street, Fort Detrick MD 21702-5014 is the awarding and administering acquisition office. The content of this publication does not necessarily reflect the position or the policy of the Government, and no official endorsement should be inferred. AAA is the recipient of a T32 Postdoctoral fellowship (NIHT32DK007774).

\section{Authors' contributions}

DJB conceived of the study, participated in its design and interpretation of results, and helped to draft the manuscript. KMS, JLC, and AAA carried out the molecular studies, participated in the design of the study and helped draft the manuscript. DOK participated in the design of the study, coordination of the experiments, analysis and interpretation and drafting the manuscript. All authors have read and approved the final version of this manuscript.

\section{Competing interests}

The authors declare that they have no competing interests.

Received: 19 July 2011 Accepted: 27 October 2011

Published: 27 October 2011

\section{References}

1. Longo MC, Berninger MS, Hartley UL: Use of uracil DNA glycosylase to control carry-over contamination in polymerase chain reactions. Gene 1990, 93:125-128.

2. Gray ER, Garson JA, Breuer J, Edwards S, Kellam P, Pillay D, Towers GJ: No Evidence of XMRV or Related Retroviruses in a London HIV-1-Positive Patient Cohort. PLoS One 2011, 6:e18096.

3. Kunstman KJ, Bhattacharya T, Flaherty J, Phair JP, Wolinsky SM: Absence of xenotropic murine leukemia virus-related virus in blood cells of men at risk for and infected with HIV. Aids 2010, 24:1784-1785.

4. Oakes B, Tai AK, Cingoz O, Henefield MH, Levine S, Coffin JM, Huber BT: Contamination of human DNA samples with mouse DNA can lead to false detection of XMRV-like sequences. Retrovirology 2010, 7:109.

5. Schlaberg R, Choe DJ, Brown KR, Thaker HM, Singh IR: XMRV is present in malignant prostatic epithelium and is associated with prostate cancer, especially high-grade tumors. Proc Natl Acad Sci USA 2009, 106:16351-16356.

6. Shin CH, Bateman L, Schlaberg R, Bunker AM, Leonard CJ, Hughen RW, Light AR, Light KC, Singh IR: Absence of XMRV and other MLV-related viruses in patients with Chronic Fatigue Syndrome. J Virol 2011.

7. Tang S, Zhao J, Viswanath R, Nyambi PN, Redd AD, Dastyar A, Spacek LA, Quinn TC, Wang X, Wood O, et al: Absence of detectable xenotropic murine leukemia virus-related virus in plasma or peripheral blood mononuclear cells of human immunodeficiency virus Type 1-infected blood donors or individuals in Africa. Transfusion 2010, 51:463-468.

8. van Kuppeveld FJ, de Jong AS, Lanke KH, Verhaegh GW, Melchers WJ, Swanink CM, Bleijenberg G, Netea MG, Galama JM, van der Meer JW: Prevalence of xenotropic murine leukaemia virus-related virus in patients with chronic fatigue syndrome in the Netherlands: retrospective analysis of samples from an established cohort. Bmj 2010, 340:C1018.

9. Verhaegh GW, de Jong AS, Smit FP, Jannink SA, Melchers WJ, Schalken JA: Prevalence of human xenotropic murine leukemia virus-related gammaretrovirus (XMRV) in Dutch prostate cancer patients. Prostate 2011, 71:415-420.

10. Aloia AL, Sfanos KS, Isaacs WB, Zheng Q, Maldarelli F, De Marzo AM, Rein A: XMRV: a new virus in prostate cancer? Cancer Res 2010, 70:10028-10033.

11. Erlwein O, Robinson MJ, Kaye S, Wills G, Izui S, Wessely S, Weber J, Cleare A, Collier D, McClure MO: Investigation into the presence of and serological response to XMRV in CFS patients. PLoS One 2011, 6:e17592. 
12. Furuta RA, Miyazawa T, Sugiyama T, Kuratsune $H$, Ikeda $Y$, Sato E, Misawa $N$, Nakatomi $Y$, Sakuma $R$, Yasui $K$, et al: No association of xenotropic murine leukemia virus-related virus with prostate cancer or chronic fatigue syndrome in Japan. Retrovirology 2011, 8:20.

13. Hong P, Li J, Li Y: Failure to detect Xenotropic murine leukaemia virusrelated virus in Chinese patients with chronic fatigue syndrome. Virol J 2010, 7:224.

14. Sakuma T, Hue S, Squillace KA, Tonne JM, Blackburn PR, Ohmine S, Thatava T, Towers GJ, Ikeda Y: No evidence of XMRV in prostate cancer cohorts in the Midwestern United States. Retrovirology 2011, 8:23.

doi:10.1186/1756-0500-4-457

Cite this article as: Bacich et al.: False negative results from using common PCR reagents. BMC Research Notes 2011 4:457.

\section{Submit your next manuscript to BioMed Central} and take full advantage of:

- Convenient online submission

- Thorough peer review

- No space constraints or color figure charges

- Immediate publication on acceptance

- Inclusion in PubMed, CAS, Scopus and Google Scholar

- Research which is freely available for redistribution

Submit your manuscript at www.biomedcentral.com/submit 